\title{
RANCANGAN APLIKASI PENDATAAN PENGUNJUNG TAMAN WISATA LEBAH PT. MADU PRAMUKA
}

\author{
Tsaniyul Iklima ${ }^{1}$, Lukman$^{2}$, Naely Farkhatin ${ }^{3}$ \\ ${ }^{1,2,3}$ Teknik Informatika,Fakultas Ilmu Komputer, Universitas Indraprasta PGRI Jakarta \\ Jalan Raya Tengah No 80, Kelurahan Gedong, Pasar Rebo, Jakarta Timur \\ 1tsaniyuliklima96@gmail.com, 21kmnaja50@gmail.com, ⒊ naely_farkhatin@yahoo.com
}

\begin{abstract}
ABSTRAK
Permasalahan pada Taman Wisata Lembah PT. Madu Pramuka terdapat pada tidak akuratnya instansi dalam proses pengolahan data pengunjung sehingga membutuhkan waktu yang lama dan pendataan pengunjung Taman Wisata Lebah masih menggunakan sistem konvensional belum menggunakan sistem komputerisasi. Tujuan merancang aplikasi ini untuk dapat memproses pengolahan data pengujung pada Taman Wisata Lebah PT. Madu Pramuka secara terkomputerisasi sehingga menghasilkan laporan yang tersimpan dengan baik dan memberikan hasil secara cepat dan akurat. Perangkat aplikasi yang telah dibuat dengan bahasa pemrograman Java NetBeans 8.0.2 dan penyimpanan data pada database MySQL dapat memberikan kelancaran dalam proses menginput dan penyimpanan data-data serta laporan-laporan yang diberikan kepada Pimpinan. Dengan menggunakan metode pengembangan sistem yaitu Waterfall dalam penelitian ini adalah dengan tahapan-tahapan seperti rekayasa sistem, analisis, desain, coding, testing, dan maintenance. Hasil dari penelitian ini menciptakan rancangan aplikasi pendataan pengunjung yang dapat memudahkan admin untuk memproses pendataan data pengunjung dan mempermudah dalam hal pencarian data serta penginputan data paket, data pengunjung, data pemesanan dan data pembayaran yang lebih baik dan akurat.
\end{abstract}

Kata Kunci: Aplikasi, Pendataan, Pengunjung, Desktop

\begin{abstract}
Problems at the Taman Wisata Lebah PT. Madu Pramuka are found in the inaccuracy of agencies in the processing of visitor data so that it takes a long time and data collection of visitors to the Bee Tourism Park is still using a conventional system yet using a computerized system. The purpose of designing this application is to be able to process data processing at the end of Taman Wisata Lebah PT. Madu Pramuka are computerized so as to produce reports that are stored properly and provide results quickly and accurately. Application devices that have been created with the Java NetBeans 8.0.2 programming language and data storage in the MYSQL database can provide smoothness in the process of inputting and storing data and reports given to the leadership. By using the system development method, namely Waterfall, in this research, the stages are systems engineering, analysis, design, coding, testing, and maintenance. The results of this study create a visitor data collection application design that can make it easier for admins to process visitor data collection and make it easier to search for data and input package data, visitor data, ordering data and payment data that is better and more accurate.
\end{abstract}

Key Word: Application, Data Collection, Visitors, Desktop

\section{PENDAHULUAN}

Perkembangan ilmu teknologi dan informasi yang berkembang saat ini sangat pesatnya sehingga membuat kita untuk tidak ketinggalan mengikuti kemajuan teknologi informasi. Kemajuan tersebut menghasilkan manfaat yang baik untuk mendorong percepatan berbagai bidang,termasuk lembaga dan instansi. Seiring dengan perkembangan teknologi yang begitu pesat, kebutuhan akan informasi sangat diperlukan, sehingga mempermudah pengguna (user) dalam melakukan suatu pekerjaan (Solikhin, Sobri, \& Saputra, 2018).

Taman Wisata Lebah didirikan pada 28 Mei 1970 atas gagasan dari Sekjen Kwatir Nasional Gerakan Pramuka,Taman Wisata Lebah berada dalam naungan PT. Madu Pramuka tang terletak di Kompleks Wiladatika Cibubur. Taman Wisata Lebah merupakan kawasan wisata edukasi bagi pelajar dan masyarakat umum (Gumanti, Utami, \& Irviani, 2020). 
Akan tetapi pengolahan data pengunjung Taman Wisata Lebah tiap bulan masih dicatat dalam sebuah buku khusus, dan untuk menyerahkan bukti laporan data pengunjung masih bersifat konvensional (Solikhin et al., 2018). Masalah yang timbul adalah ketidak konsistenan data yang dapat menyebabkan kerangkapan data,apabila dalam pencarian data membutuhkan waktu yang sangat lama karena masih menggunakan sistem yang konvensional,dan keamanan data pun masih kurang terjamin (Listiani, SUF, \& Gunawan, 2019).

Permasalahan yang terdapat pada Taman Wisata Lebah PT. Madu Pramuka adalah masih tidak akuratnya instansi dalam proses pengolahan data pengunjung sehingga membutuhkan waktu yang lama. Proses pendataan pengunjung Taman Wisata Lebah masih menggunakan sistem konvensional belum menggunakan sistem komputerisasi dan mekanisme pelaporan untuk pendataan pengunjung Taman Wisata Lebah masih belum terorganisir dengan baik (Idola Perdini Putri, Asti Widayanti, Kastaman, Reni Nuraeni, Irna Yuniar, 2016).

Dengan permasalahan tersebut, perlu ada nya suatu sistem yang terkomputerisasi dalam penyelesaiannya. Sistem adalah sekelompok unsur yang erat hubungannya satu dengan yang lain, yang berfungsi bersama-sama untuk mencapai tujuan (Sutabri, 2012). Sistem merupakan suatu kumpulan dari komponenkomponen yang membentuk satu kesatuan (Tyoso, 2016). Pembangunan sistem adalah sekumpulan aktivitas yang menggambarkan secara rinci bagaimana sistem akan berjalan. Hal itu bertujuan untuk menghasilkan produk perangkat lunak yang sesuai dengan kebutuhan user (Satzinger, J. W., Jackson, R. B., Burd, n.d.).

Diharapkan dengan adanya suatu sistem informasi dapat menangani permasalahan yang ada di perusahaan tersebut. Sistem adalah setiap sesuatu terdiri dari obyek-obyek, atau unsurunsur, atau komponen-komponen yang bertata kaitan dan bertata hubungan satu sama lain, sedemikian rupa sehingga unsur-unsur tersebut merupakan satu kesatuan pemrosesan atau pengolahan yang tertentu (Prasojo, 2011).
Rancangan aplikasi ini dapat memudahkan pekerjaan petugas yaitu Admin dalam proses pendataan serta melaksanakan pembuatan laporan dan dapat memudahkan perusahaan dalam mengontrol pengunjung yang datang sehingga dapat membantu dan mempercepat kinerja bagian administrasi dalam membuat laporan perbulan. Aplikasi pengolahan data pengunjung secara terkomputerisasi sehingga menghasilkan laporan yang tersimpan dengan baik dan memberikan hasil secara cepat dan akurat.

\section{METODE PENELITIAN}

Peneliti menggunakan metode Research and Development dalam penyelesaian penelitian ini. (Sugiyono, 2016). Metode penelitian dan pengembangan atau dalam bahasa Inggrisnya Research and Development adalah metode penelitian yang digunakan untuk menghasilkan produk tertentu, dan menguji keefektifan produk tersebut. Produk tersebut tidak selalu berbentuk benda atau perangkat keras (hardware), seperti buku, alat tulis, dan alat pembelajaran lainnya. Akan tetapi, dapat pula dalam bentuk perangkat lunak (software). Dalam hal ini penelitian yang dilakukan dengan merancang suatu perangkat lunak ataupun sistem informasi untuk proses pengolahan data pengunjung pada Taman Wisata Lebah PT. Madu Pramuka yang sesuai dengan kebutuhan (Kurniawan \& Tanjung, 2017).

Dalam pelaksanaan R\&D, ada beberapa metode yang digunakan yaitu metode deskriptif, evaluatif dan eksperimental. Metode penelitian deskriptif digunakan dalam penelitian awal untuk menghimpun data tentang kondisi yang ada yaitu penulis membutuhkan data-data yang dapat menunjang terciptanya suatu sistem informasi pengolahan data pengunjung seperti data pengunjung, data tiket pengunjung, data pemesanan tiket pengunjung, dan data pembayaran tiket pengunjung terdahulu yang masih tersimpan secara manual didalam buku besar. Metode evaluatif digunakan untuk mengevaluasi proses ujicoba pengembangan suatu produk, dalam proses ini penulis melakukan ujicoba terhadap suatu sistem yang telah dirancang agar tidak ada terjadi kesalahan dalam proses penginputan data serta pelaporan 
bulanan kepada pimpinan. Dan metode eksperimen digunakan untuk menguji keampuhan dari produk yang dihasilkan, dalam proses yang terakhir ini perlu dilakukan pengujian akhir yang diharapkan bahwa sistem yang dirancang oleh penulis dapat berjalan dengan baik dan sesuai dengan kebutuhan dan terfokus pada proses pengolahan data pengunjung pada Taman Wisata Lebah PT. Madu Pramuka.

\section{HASIL DAN PEMBAHASAN}

\section{Alternatif Penyelesaian Masalah}

Berdasarkan permasalahan yang terjadi pada sistem informasi pendataan pengunjung pada Taman Wisata Lebah PT. Madu Pramuka, maka diperlukan alternatif penyelesaian masalah oleh suatu sistem. Dimana dalam proses pendataan pengunjung, proses pemesanan, pencarian data, pembuatan tiket serta pembuatan laporan dapat menjadi cepat, efektif dan efisien. Maka penyelesaian nya yaitu dengan membuat aplikasi pendataan pengunjung yang dapat diakses dengan mudah dan cepat (Idola Perdini Putri, Asti Widayanti, Kastaman, Reni Nuraeni, Irna Yuniar, 2016).

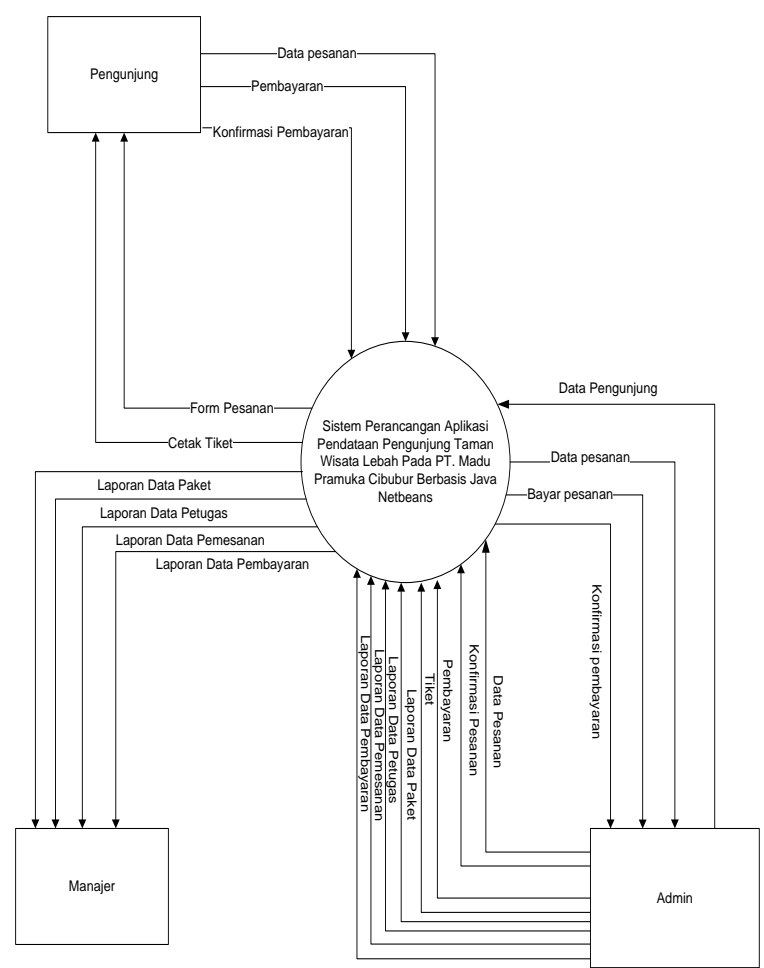

Gambar 1. Diagram Konteks

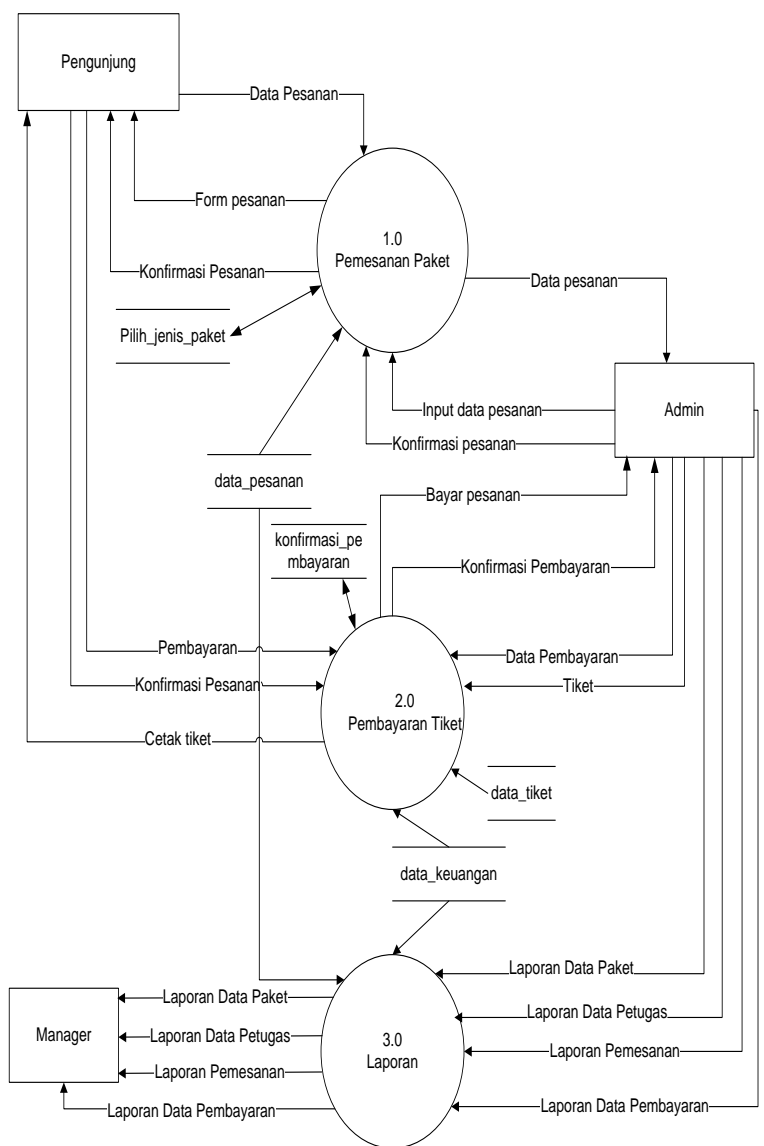

Gambar 2. Diagram Nol

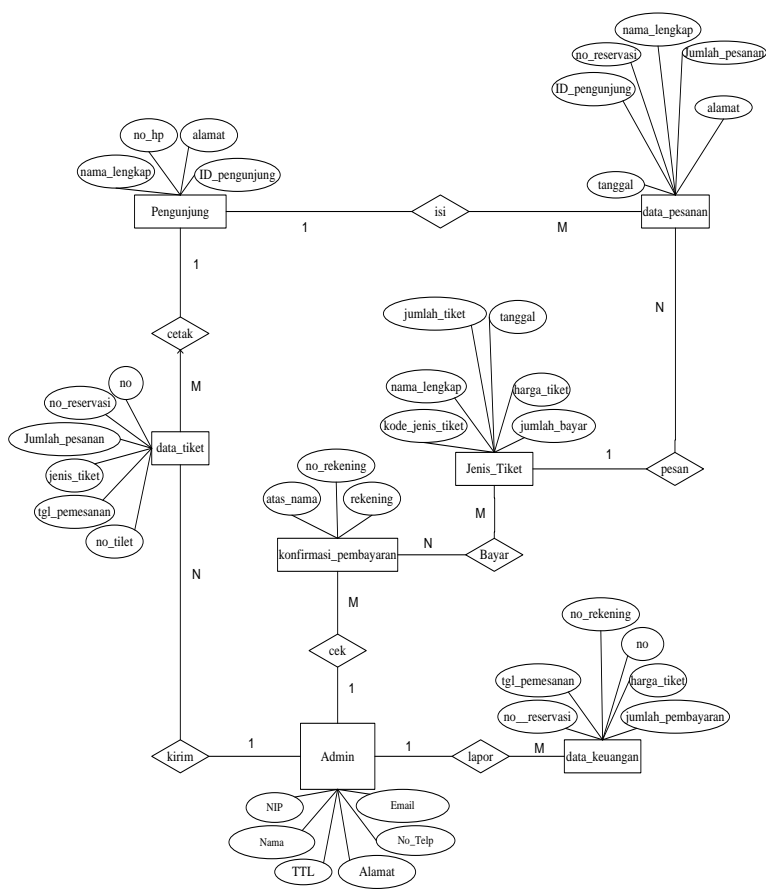

Gambar 3. ERD (Entity Relationship Diagram) 
Berikut adalah tampilan layar dan hasil pengujian pada software program yang telah di buat dengan bahasa pemrograman Java.

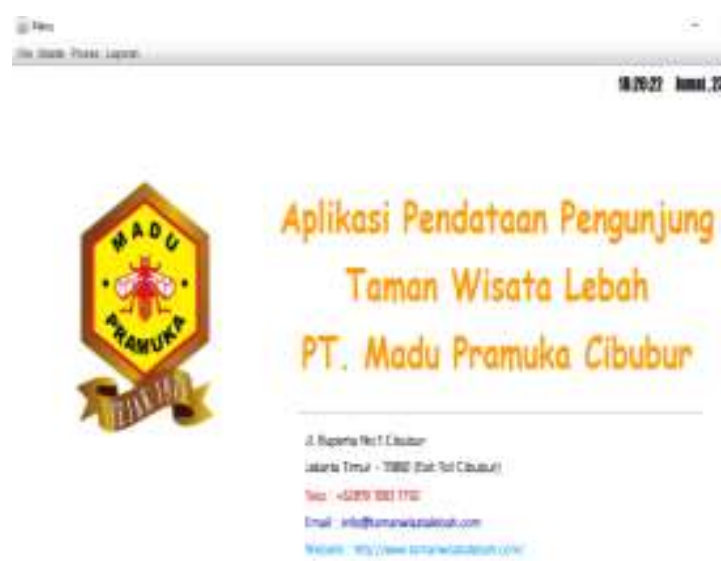

Gambar 4. Form Menu Utama

Layar di atas menampilkan tampilan Menu Utama pada Aplikasi Pendataan Pengunjung Taman Wisata Lebah PT. Madu Pramuka Cibubur. Pada layar utama tersedia menu bar yang terdiri dari master data yang digunakan untuk memasukkan data yang berkaitan dengan data paket, data petugas, data pemesanan, data pembayaran, dan laporan-laporan.

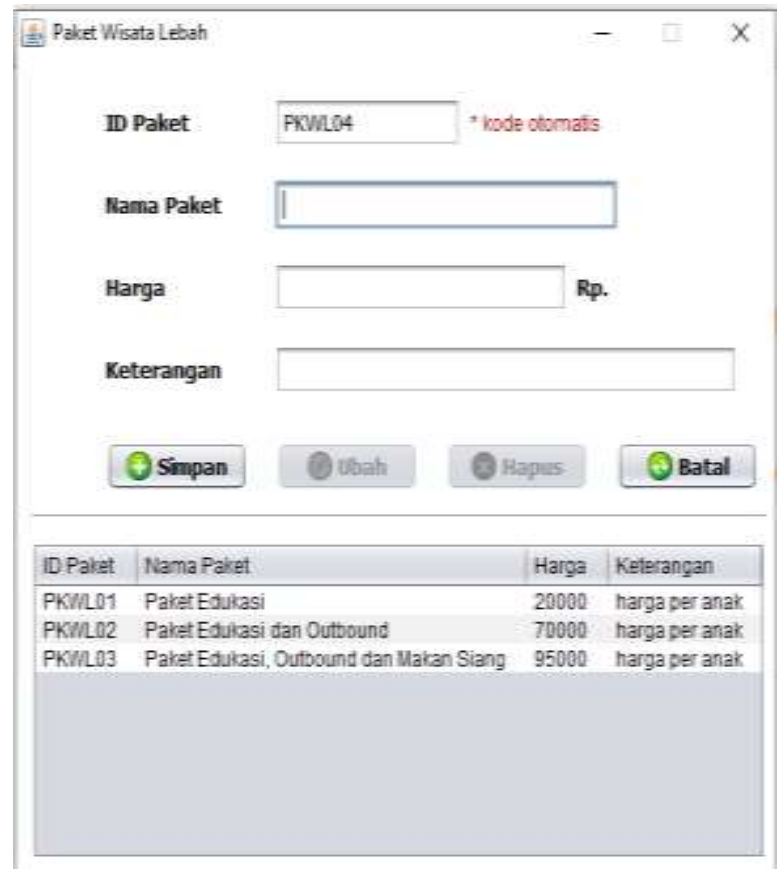

Gambar 5. Form Data Paket

Layar di atas menampilkan tampilan form data paket. Pada layar form data paket untuk meng- input data paket yang terdiri dari ID Paket, Nama Paket, Harga dan Keterangan.

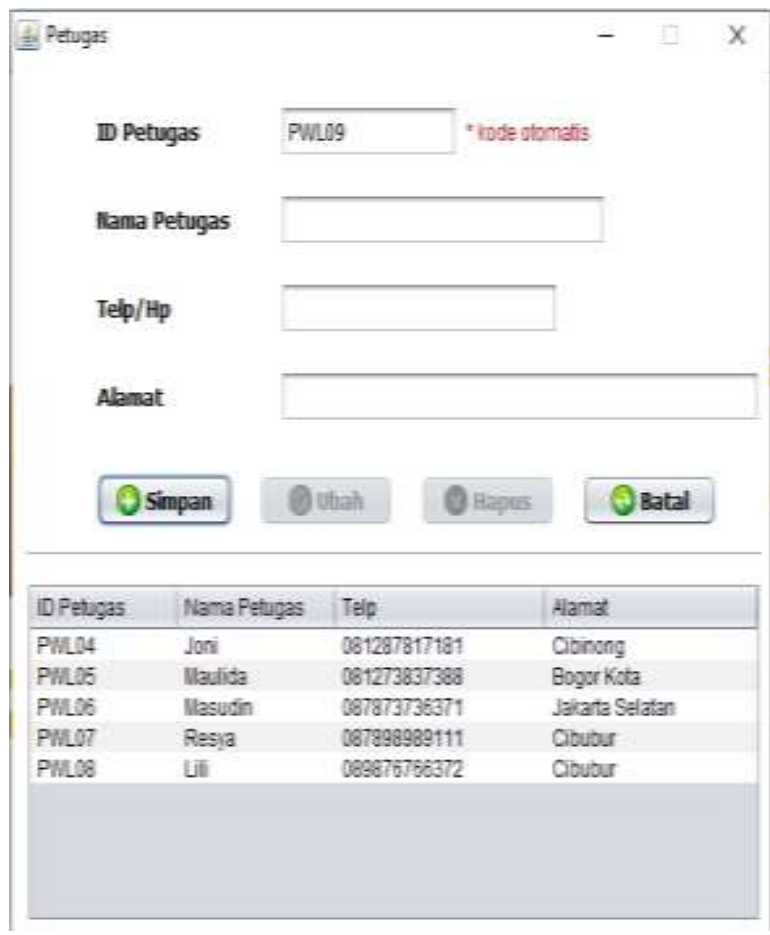

Gambar 6. Form Data Petugas

Layar di atas menampilkan tampilan form data petugas. Pada layar form data petugas untuk meng-input data petugas yang terdiri dari ID Petugas, Nama Petugas, Telp dan Alamat.

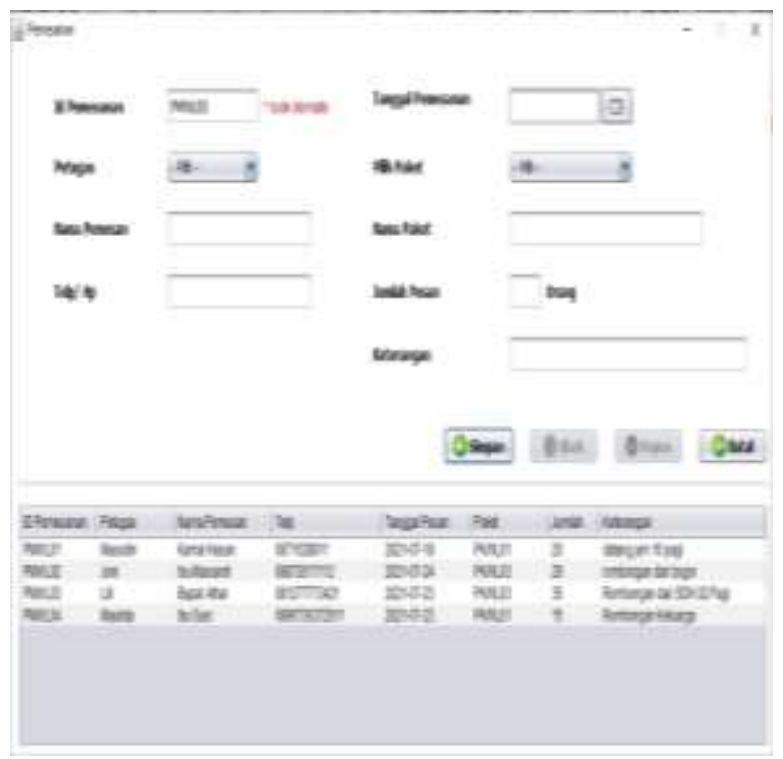

Gambar 7. Data Form Data Pemesanan 
Layar di atas menampilkan tampilan form data pemesanan. Pada layar form data pemesanan untuk meng-input data pemesanan yang terdiri dari ID Pemesanan, Nama Petugas, Nama Pemesan, Telp, Tanggal Pesan, ID Paket, Jumlah dan Keterangan.

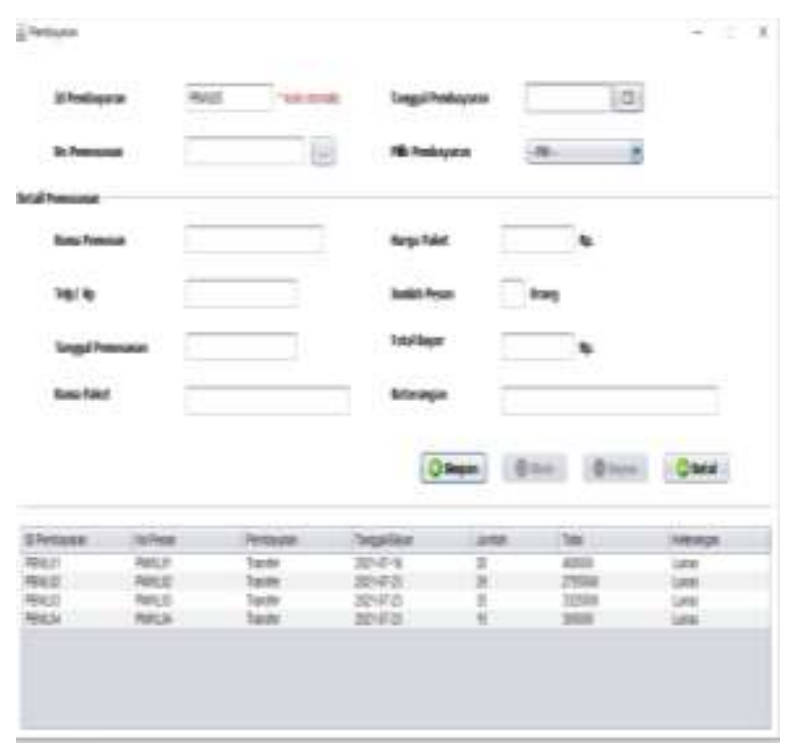

Gambar 8. Form Data Pembayaran

Layar di atas menampilkan tampilan form data transaksi pembayaran. Pada layar form data transaksi pembayaran untuk meng-input data transaksi pembayaran yang terdiri dari ID Pembayaran, No Pemesanan, Tanggal Pembayaran, Pilih Pembayaran, Nama Pemesan, Telp/HP, Tanggal Pemesanan, Nama Paket, Harga Paket, Jumlah Pesan, Total Bayar dan Keterangan.

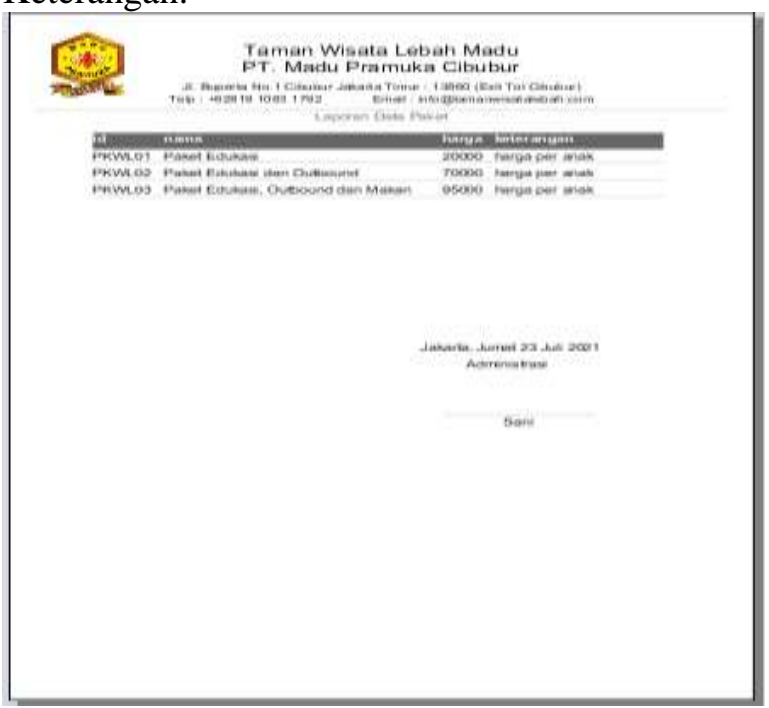

Gambar 9. Laporan Data Paket
Layar di atas menampilkan tampilan form laporan data paket. Pada layar form data paket digunakan untuk mengecek laporan data paket terdiri ID Paket, Nama Paket, Harga dan Keterangan.

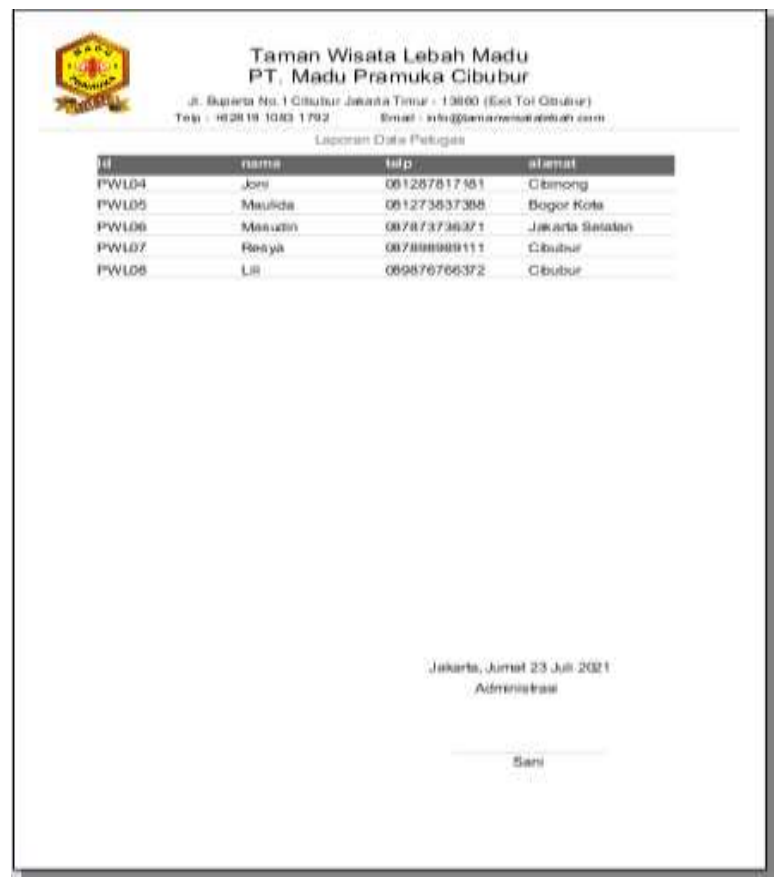

Gambar 10. Laporan Data Petugas

Layar di atas menampilkan tampilan form laporan data petugas. Pada layar form data petugas digunakan untuk mengecek laporan data petugas terdiri ID Petugas, Nama Petugas, Telp/HP dan Alamat.

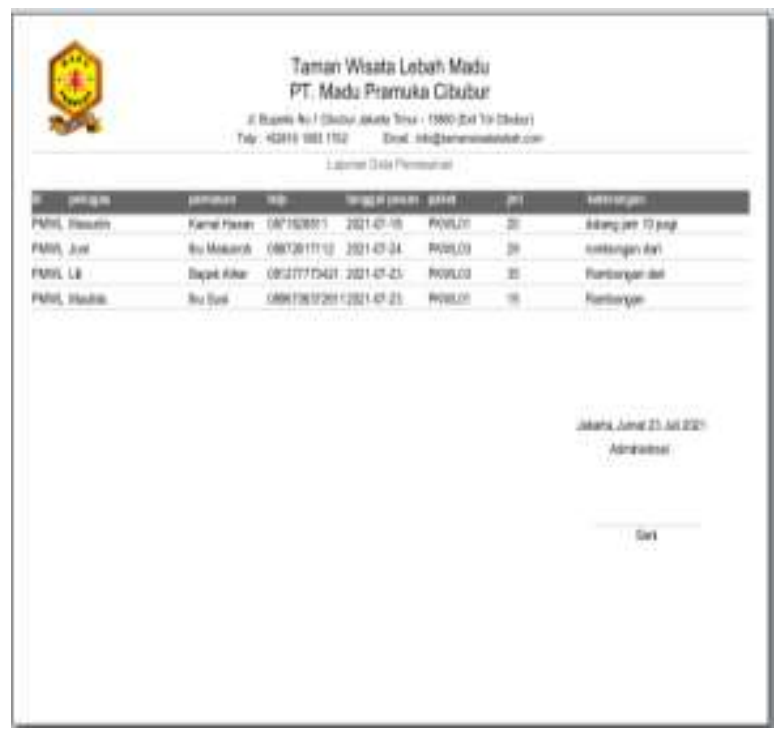

Gambar 11. Laporan Data Pemesanan 
Layar di atas menampilkan tampilan form laporan data pemesanan. Pada layar form data pemesanan digunakan untuk mengecek laporan data pemesanan terdiri ID Pemesanan, Nama Petugas, Nama Pemesan, Telp, Tanggal Pesan, ID Paket, Jumlah dan Keterangan.

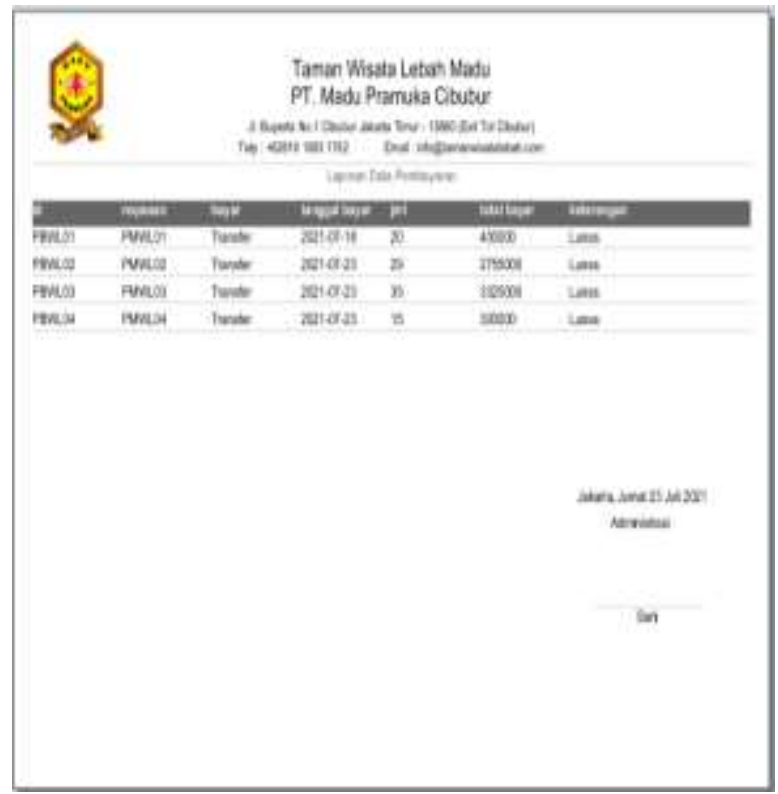

Gambar 12. Laporan Data Pembayaran

Layar di atas menampilkan tampilan form laporan data pembayaran. Pada layar form data pembayaran digunakan untuk mengecek laporan data pembayaran terdiri ID Pembayaran, No Pemesanan, Jenis Pembayaran, Tanggal Bayar, Jumlah, Total Bayar dan Keterangan.

\section{SIMPULAN DAN SARAN}

Aplikasi berbasis desktop yang dapat memproses pengolahan data pengunjung pada Taman Wisata Lebah PT. Madu Pramuka secara terkomputerisasi sehingga dapat membantu dan mempercepat kinerja bagian administrasi dalam membuat laporan perbulan. Aplikasi pengolahan data pengunjung secara terkomputerisasi sehingga menghasilkan laporan yang tersimpan dengan baik dan memberikan hasil secara cepat dan akurat.

Saran sebelum sistem baru dilaksanakan, sebaiknya seluruh pihak perusahaan yang terkait dalam sistem harus diberikan penjelasan dengan baik terlebih dahulu mengenai proses kerja sistem yang akan diterapkan sehingga tidak terjadi kekeliruan. Serta perlu dilakukan pelatihan penggunaan sistem tersebut terhadap personil yang terlibat dalam sistem ini agar mereka dapat mengetahui dan memahami cara kerja sistem yang baru.

\section{DAFTAR PUSTAKA}

Gumanti, M., Utami, B. H. S., \& Irviani, R. (2020). ETicket: Aplikasi Efektif Dalam Menghadapi New Normal Covid-19 Bagi Pengunjung Wisata Talang Indah Kabupaten Pringsewu. Prosiding Snitt Poltekba, 4, 93-100. Retrieved from https://jurnal.poltekba.ac.id/index.php/prosidin g/article/view/1003

Idola Perdini Putri, Asti Widayanti, Kastaman, Reni Nuraeni, Irna Yuniar, A. A. (2016). Implementasi Aplikasi Pencatatan Pengunjung, Pendapatan dan Informasi Melalui QR Code di Museum Sri Baduga Bandung. Jurnal Aplikasi Ipteks Untuk Masyarakat, 10(1), 31-37. https://doi.org/10.24198/dharmakarya.v10i1.23 942

Kurniawan, H., \& Tanjung, M. R. (2017). Sistem Informasi Geografis Objek Wisata Alam di Provinsi Sumatera Utara Berbasis Mobile Android Geographic Information System Object of Natural Tourism in North Sumatra Province Based Mobile Android. Jurnal Ilmiah SISFOTENIKA, VII(1), 13-24.

Listiani, D., SUF, S., \& Gunawan, W. (2019). Rancang Bangun Sistem Aplikasi E-Ticket Pada Museum Nasional Indonesia Berbasis Android. Format: Jurnal Ilmiah Teknik Informatika, 8(1), 26. https://doi.org/10.22441/format.2019.v8.i1/004

Prasojo, M. (2011). Pengantar Sistem Informasi Manajemen . bandung: CV. Remadja Karya.

Satzinger, J. W., Jackson, R. B., Burd, S. D. (n.d.). System Analysis and Design in A Changing World. USA: Cengage Learning.

Solikhin, I., Sobri, M., \& Saputra, R. (2018). Sistem Informasi Pendataan Pengunjung Perpustakaan (Studi Kasus: SMKN 1 Palembang). Jurnal Ilmiah Betrik, 9(03), 140-151.

Sugiyono. (2016). Metode Penelitian Kuantitatif, Kualitatif dan $R \& D$. Bandung: PT Alfabet.

Sutabri, T. (2012). Analisis Sistem Informasi. Yogyakarta: Andi.

Tyoso, J. S. P. (2016). Sistem Informasi Manajemen. Yogyakarta: DeePublish. 